\title{
Intrauterine Hydrocephalus and Ventriculomegaly: Associated Abnomalies and Fetal Outcome
}

\author{
D. D. Cochrane, S. T. Myles, C. Nimrod, D. K. Still, R. G. Sugarman and B. K. Wittmann
}

ABSTRACT: Advances in fetal diagnostic techniques have opened many areas to prenatal anatomical scrutiny. Intrauterine hydrocephalus and ventriculomegaly are conditions which are readily diagnosed. Fetal intervention has been undertaken in humans in order to minimize the craniofacial disfigurement and to maximize the growth potential of the brain. To justify such an approach, the significance of all anomalies should be recognized prior to treatment. The authors have reviewed 41 cases of hydrocephalus diagnosed in utero in order to define associated anomalies and patient outcome.

$75 \%$ of our personal series and $72 \%$ of the reviewed literature cases had other anomalies of the central nervous system. Other system malformations, some of which proved fatal, were seen commonly. Prenatal diagnostic techniques did not always reveal these additional problems.

The outcome of these pregnancies is not good. Approximately one third of these fetuses have survived to be treated postnatally and to be followed up clinically. Only $7.5 \%$ of this series were felt to have attained normal developmental milestones. The remainder of the survivors have various focal and/or global cerebral deficits.

RÉSUMÉ: Hydrocéphalie Intra-Utérine L'introduction de nouvelles techniques diagnostiques a permis d'ouvrir plusieurs avenues d'investigation anatomique prénatale. Parmi les conditions facilement diagnostiquées ainsi se trouve l'hydrocéphalie intra-utérine. Des interventions foetales ont pu être accomplies chez l'humain afin de minimiser les malformations cranio-faciales et de maximiser le potentiel de croissance du cerveau. Afin de justifier une telle approche, la signification de chacune des anomalies doit être reconnue avant le traitement. Les auteurs ont revu 82 cas d'hydrocéphalie diagnostiquée in utero afin de définir les anomalies associées et l'évolution.

68\% de nos patients et $87 \%$ des cas dans la littérature avaient d'autres anomalies du système nerveux central. D'autres malformations systémiques, dont certaines fatales, sont fréquemment observées. Les techniques de diagnostic prénatal n'avaient pas toujours identifié ces malformations.

Le résultat de ces grossesses n'est pas bon. Environ le tiers des foetus ont survécu pour être traités de façon post-natale et être suivis cliniquement. Seulement $10 \%$ des cas de la série entière atteignent des plateaux normaux de développment. Chez les autres survivants on retrouve des déficits cérébraux focaux ou généralisés variables.

Can. J. Neurol. Sci. 1985; 12:51-59

The recent medical literature has witnessed a flood of articles discussing the problem of hydrocephalus and ventriculomegaly diagnosed in utero. Many review the ultrasonic diagnosis, others deal with exciting and innovative surgical attempts to treat such patients. There has not been a great deal of attention paid to the nature of the developmental anomalies seen in these patients. It is the purpose of this paper to review a series of patients diagnosed as having ventriculomegaly in utero in order to shed light on the developmental outcome, and the pathological anatomy of the central nervous and other body systems recognized in association with this entity.

\section{METHODS}

Forty-one cases, from four institutions providing care to high risk obstetrical and neonatal patients, were reviewed (Table 1). The reasons for the initial ultrasound examination and the prenatal diagnoses were determined. Ventriculomegaly was

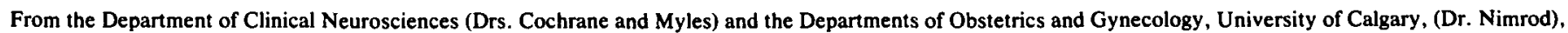

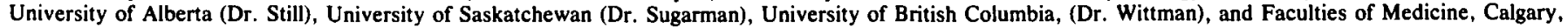
Edmonton, Saskatoon and Vancouver.

Received October 22, 1984. Accepted December 21, 1984.

Reprint requests to: Dr. D. D. Cochrane, Suite 207, 803 - 1 Avenue N.E., Calgary, Alberta, Canada T2E 7C5. 
Table 1: Clinical Details for the Current Series. Abbreviations: SBO - spina bifida occulta, MMC - myelomeningocele, SP - septum pellucidum, CC - corpus callosum, PDA - patent ductus arteriosus, VER - visual evoked potential, TEF - tracheoesophageal fistula, PF - posterior fossa, E - Elective

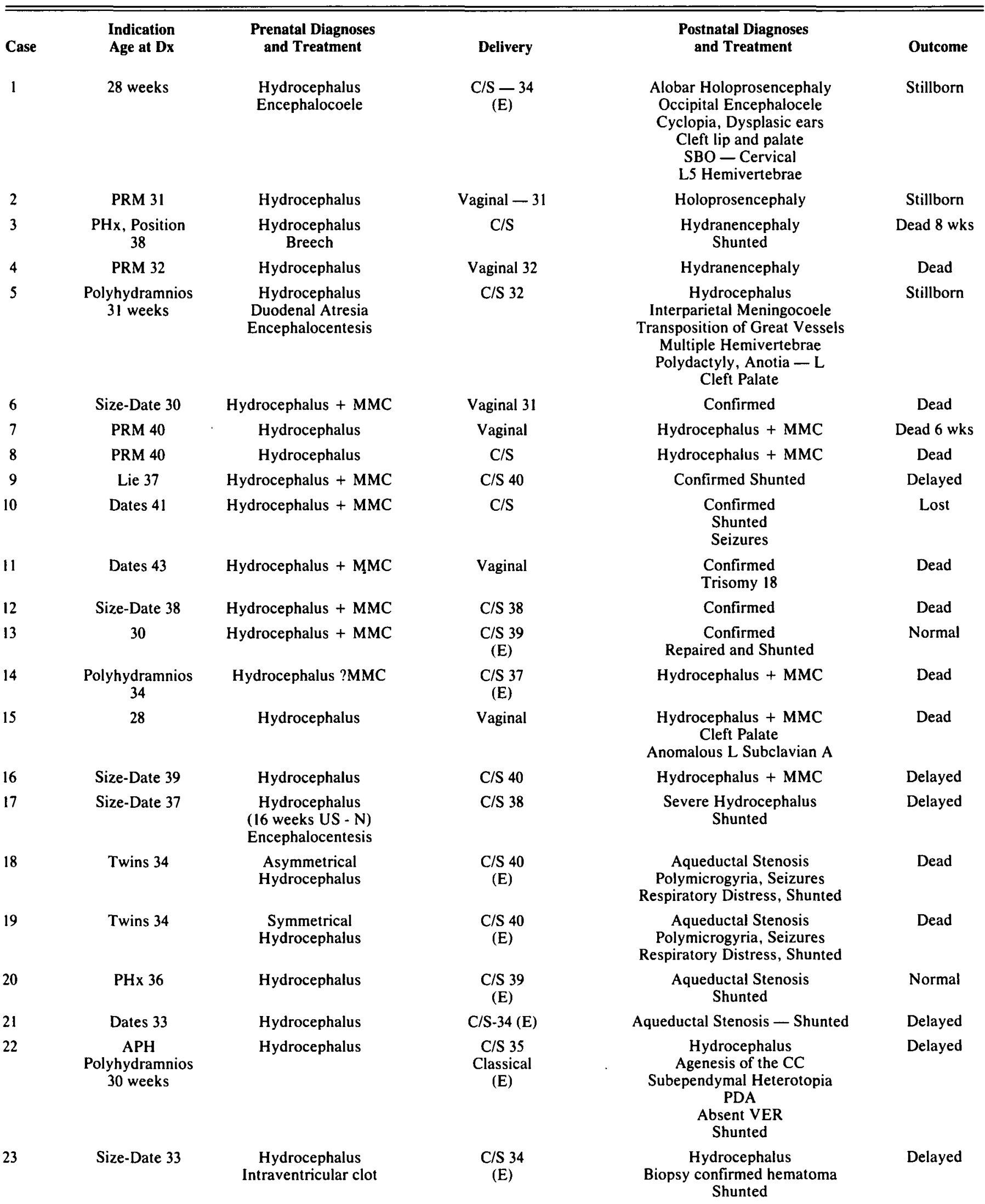




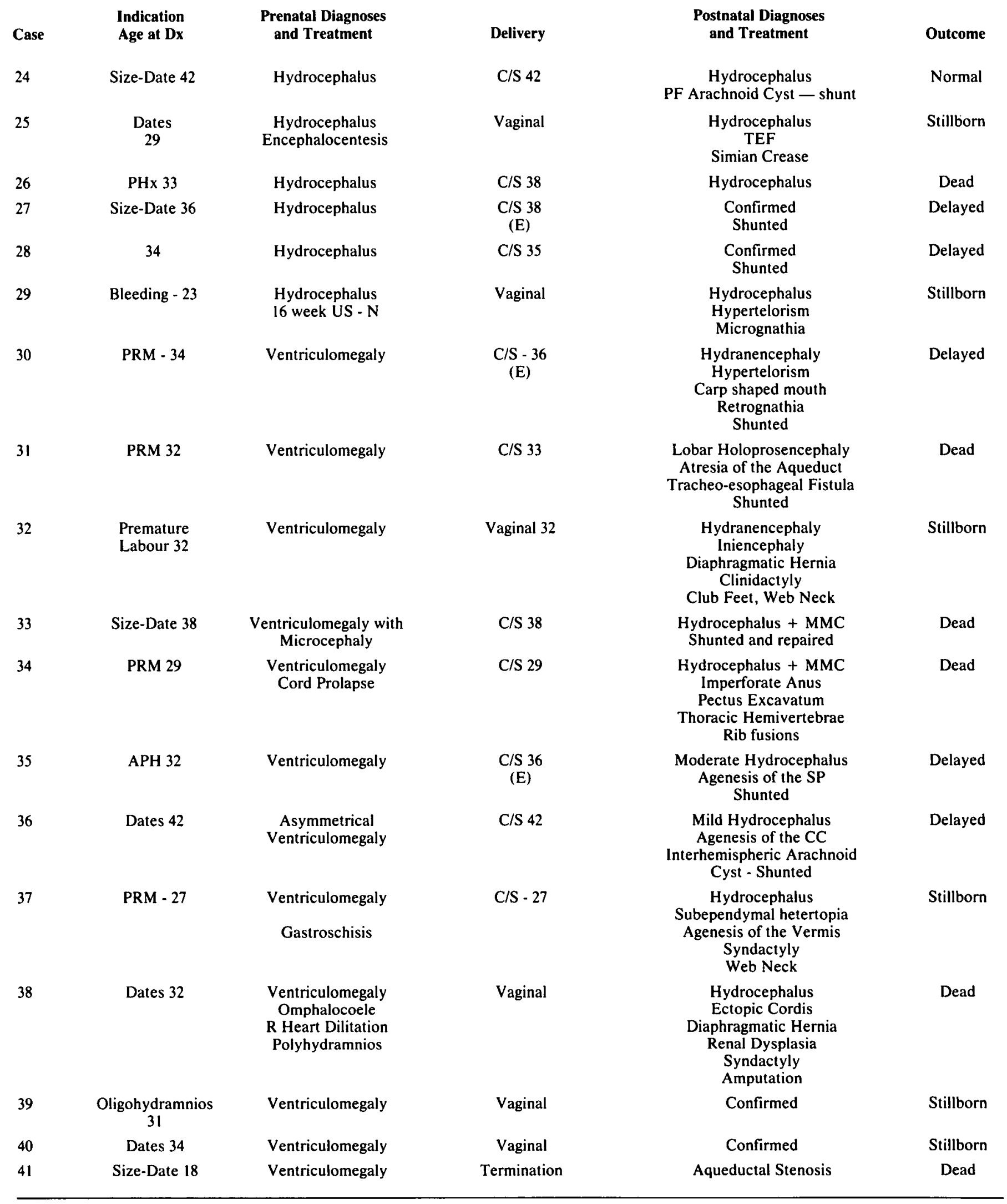


diagnosed if ventricular enlargement was stable or documented on only one study prior to delivery; the diagnosis of hydrocephalus required the presence of either progressive ventricular enlargement, or associated craniomegaly. Those cases with prenatally diagnosed malformations that postnatally are seen in association with hydrocephalus, also were termed hydrocephalic. Comparison of the pre and postnatal diagnoses were made possible by postnatal physical examination, neuroradiography, or autopsy, if stillborn. Many had postnatal ultrasound examinations or CT scans. Obstetrical interventions and case outcome were determined by chart review and clinical followup.

\section{Results}

\section{Maternal Data}

The multiparous pregnancies exceed the primiparous by a ratio of two to one. The majority of mothers were between the ages of 20 and 30 years $(66 \%)$. The indications for ultrasound examination and the distribution of gestational ages at the time of diagnosis of fetal ventriculomegaly is given in Figure 1. Only two cases were recognized at less than 24 weeks gestation. The majority were seen in the last 10 weeks of gestation.

The indications for prenatal ultrasonic examination were varied. The primary reasons were obstetrical. Only two families with a past history of a hydrocephalic infant were recognized. Their studies were falsely reassuring early in pregnancy. In each case the ventriculomegaly was not seen until after 20 weeks.

Obstetrical indications for ultrasonic assessment included size-date discrepancy for a variety of reasons including polyhydramnios, premature rupture of the membranes (PRM) and antepartum hemorrhage (APH). Twinning was diagnosed in one pregnancy. Concern regarding the identity of the presenting part was also a reason for investigation (Presentation) (Figure 1).

\section{Prenatal Diagnoses}

In all 41 cases, the diagnosis of ventriculomegaly or hydrocephalus was made prior to delivery. Ventriculomegaly was seen in 12 cases and hydrocephalus in 29 . The degree of ventricular enlargement varied appreciably. Only 2 cases had detectable ventricular assymmetry. Six fetuses had dysraphic spines recognized. One patient had an encephalocele and one had an intrauterine intraventricular hemorrhage in association with the hydrocephalus. Abnormalities of other systems were seen in only 3 cases (gastroschisis, omphalocele, duodenal atresia, right heart dilatation. Prenatally, $70 \%$ of the fetuses were felt to have only ventricular enlargement.

\section{Delivery}

A hysterotomy was performed at 24 weeks in one case. This female fetus had aqueductal stenosis and massive hydrocephalus. No other therapeutic terminations were included because of the difficulty obtaining adequate pathological studies in such cases.

Vaginal delivery was used in twelve pregnancies. All vaginally delivered patients were stillborn or died in the immediate postpartum period. Encephalocentesis was used in one of these cases to facilitate delivery.

Caesarean section was the commonest method of delivery for these patients. Two neonates required encephalocentesis for delivery. One is a survivor. Two mothers underwent classical section to deliver the fetal head.

Sixteen fetuses were delivered by Caesarean section, just prior to the expected date of confinement or after the onset of premature labour in order to effect an atraumatic delivery. Five infants died due to their anomalies, nine are delayed in development, and two are normal (one has a repaired myelomeningocele and shunted hydrocephalus; the other, has shunted hydrocephalus due to a posterior fossa arachnoid cyst).

Elective Caesarean section was undertaken in 12 pregnancies to allow earlier postnatal treatment of the hydrocephalic fetus. Four of these newborns died, two with complications of prematurity and seizures, one was granted compassionate care only, and one was stillborn. The remaining eight patients include one normal male with aqueductal stenosis (shunted), one normal child with a myelomeningocele and shunted hydrocephalus, and six cases of shunted hydrocephalus, all of whom have various cerebral deficits.

\section{Developmental anomalies recognized after birth}

The postnatal assessment of these pregnancies, whether clinical and radiographic or pathological, illustrates the variety of

Figure 1 - Obstetricallndicationsand Gestational Age at Diagnosis. The number of patients is plotted against the gestational age at ultrasound diagnosis coupled with the indications for the study. Antepartum hemorrhage - APH, Premature rupture of membranes - PRM

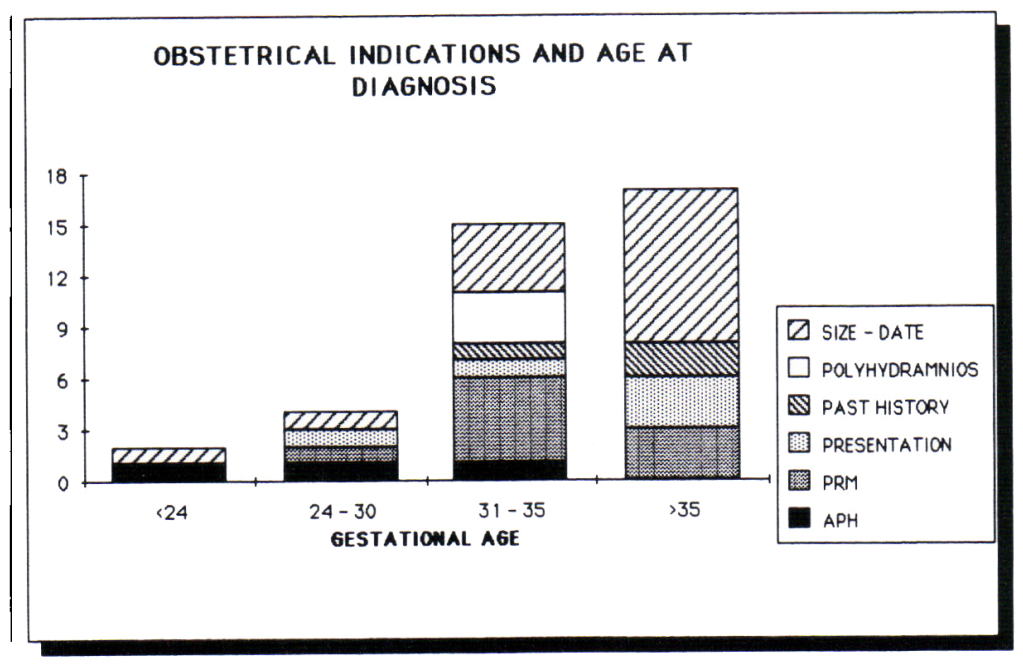


abnormalities seen in association with ventricular enlargement diagnosed in utero. (Tables 2 and 3)

\section{Central Nervous System Abnormalities (Table 2)}

Ventricular enlargement was judged mild in only 4 cases. Based on the head circumference, postnatal ultrasound examination or computed cerebral tomography, 30 patients had severe lateral ventriculomegaly. Hydranencephaly was diagnosed postnatally in 4 cases and holoprosencephaly (2-alobar, 1-lobar) in 3 cases.

One occipital encephalocoele was recognized in utero; one stillborn fetus had an interparietal meningocoele. Iniencephaly was found in one case. Five unrecognized myelomeningoceles were noted at delivery (an additional 6 were documented prior to birth).

Structural abnormalities included agenesis of the corpus callosum and septum pellucidum. Polymicrogyria, subedpendymal nodules and heterotopias were seen. Two patients had arachnoidal cysts, one in the posterior fossa and one in the interhemispheric area associated with agenesis of the corpus callosum. One child had had an intraventricular hematoma recognized prior to birth and this was confirmed histologically by ventriculoscopic biopsy at the time of shunting.

\section{Facial Anomalies}

Various forms of facial dysmorphism were seen in the stillborn group. Cyclopia and anotia were present in one case each. Cleft palate and lips, and hypertelorism were seen in 3 and 2 cases respectively. Retrognathia and a 'carp-shaped mouth' were present in one patient.

\section{Cardiovascular Anomalies}

A variety of both lethal and nonlethal cardiac anomalies were noted in 4 patients. These included transposition of the great vessels, an atrial septal defect and pulmonary atresia, ectopic cordis, anomalous left subclavian arteries and one patent ductus arteriosus.

\section{Gastrointestinal Anomalies}

Gastroschisis was confirmed in one patient. Two unrecognized diaphragmatic herniae were demonstrated after birth. Two children had tracheoesophageal fistulae with esophageal atresia and one had an imperforate anus.

\section{Renal Anomalies}

Dysplasia of one kidney and agenesis of another were the only renal problems recognized in the non-myelomeningocele patients.

\section{Skeletal Anomalies}

Spinal disorders in non-myelomeningocele patients were limited to a webbed neck in 2 cases, hemivertebrae in three, and one child with cervical spina bifida occulta.

Limb abnormalities included polydactyly, clinodactyly and syndactyly. One amputation due to an amniotic band was seen.

\section{Chromosomal Abnormalities}

One pregnancy produced a liveborn infant with Trisomy 18.

\section{Outcome of Hydrocephalus diagnosed in utero}

In our 41 cases, pregnancy ended in stillbirths in 9 cases. Seven of these cases had additional anomalies of the central nervous system and/or other organs. Six were delivered vaginally.

There were 32 live births in this series. The treatment afforded the neonate and the family was individualized as was deemed appropriate by all concerned parties. Twelve children expired without treatment directed to their hydrocephalus. Eight had extensive myelomeningoceles associated with a complete cord lesion. One child was hydranencephalic and one had ectopic cordis along with renal agenesis. Two had massive hydrocephalus alone.

Table 2: The Incidence of Central Nervous System Anomalies Recognized in Association with Ventriculomegaly Diagnosed in Utero

\begin{tabular}{|c|c|c|c|}
\hline & \multicolumn{2}{|c|}{ Case Incidence (\%) } & \multirow[t]{2}{*}{ References } \\
\hline & $\begin{array}{l}\text { Current } \\
\text { Series }\end{array}$ & $\begin{array}{l}\text { Literature } \\
\text { Series }\end{array}$ & \\
\hline Central Nervous System & $75 \%$ & $72 \%$ & \\
\hline Myelomeningocele & 27 & 25 & $4,12,17,18,23,30,31$ \\
\hline Hydranencephaly & 10 & 2 & 21,31 \\
\hline Holoprosencephaly & 7 & 4 & 5,31 \\
\hline Heterotopia & 5 & & \\
\hline $\begin{array}{l}\text { Agenesis of Corpus } \\
\text { Callosum }\end{array}$ & 5 & 7.5 & $1,10,30,31$ \\
\hline Polymicrogyria & 5 & 1 & 18 \\
\hline Arachnoidal Cyst & 5 & 2.5 & 30 \\
\hline Encephalocele & 5 & 5 & $17,25,30,31$ \\
\hline Iniencephaly & 2 & & \\
\hline $\begin{array}{l}\text { Agenesis of Septum } \\
\text { Pellucidum }\end{array}$ & 2 & 4 & $2,10,31$ \\
\hline $\begin{array}{l}\text { Intraventricular } \\
\text { Hemorrhage }\end{array}$ & 2 & & \\
\hline Dandy-Walker Syndrome & & 7.5 & $7-9,15,19,22$ \\
\hline Hydrolethaus Syndrome & & 10.5 & 13,28 \\
\hline Infection & & 2 & 2,17 \\
\hline Porencephaly & & 1 & 31 \\
\hline
\end{tabular}

Table 3: The Incidence of Non-Central Nervous System Anomalies Recognized in Association with Ventriculomegaly Diagnosed in Utero

\begin{tabular}{|c|c|c|c|}
\hline \multirow[t]{2}{*}{ System Anomaly } & \multicolumn{2}{|c|}{ Case Incidence (\%) } & \multirow[t]{2}{*}{ References } \\
\hline & $\begin{array}{l}\text { Current } \\
\text { Series }\end{array}$ & $\begin{array}{l}\text { Literature } \\
\text { Series }\end{array}$ & \\
\hline Facial & $10 \%$ & $5 \%$ & $10,11,31$ \\
\hline Cardiac & $10 \%$ & $15 \%$ & $3,6,10,14,18,23,31$ \\
\hline Gastrointestinal & $7 \%$ & $5 \%$ & $14,23,31$ \\
\hline Genitourinary & $5 \%$ & $2 \%$ & 10,31 \\
\hline Skeletal - Limb & $10 \%$ & $7 \%$ & $10,14,22$ \\
\hline Spinal & $10 \%$ & $2 \%$ & 26 \\
\hline
\end{tabular}


Ventriculoperitoneal shunts were inserted in patients postnatally when signs of increased intracranial pressure and/or progressive craniomegaly became evident.

Of those children shunted, five have died. One had hydraencephaly and was shunted to facilitate nursing care. One neonate had holoprosencephaly and a tracheoesophageal fistula. Two died of the pulmonary complications of prematurity and uncontrollable seizures. One infant with a repaired myelomeningocoele and a shunt died unexpectedly at age 3 months.

Developmental milestones (motor and speech) have been delayed in eleven treated patients. Two underwent closure of their dysraphic spinal lesion and shunting. Their delay is not attributable to their spinal handicap. Agenesis of the corpus callosum is present in two (one also has interhemispheric arachnoidal cysts) and agenesis of the septum pellucidum in one. Obstructive hydrocephalus (aqueductal stenosis) was proven in one. The remainder have communicating hydrocephalus. The child with hydrocephalus secondary to a recognized intrauterine intraventricular hemorrhage is dysphasic, hemiparetic and has seizures, although he is able to use sign language effectively.

Normal development to date has been seen in only 3 patients. The follow up is over 2 years in all cases. One patient has a myelomeningocoele, one has $\mathrm{X}$-linked recessive aqueductal stenosis and one has a posterior fossa arachnoidal cyst. All three had postnatal shunts inserted. None have had shunt infections to date. One patient was lost to follow up (Case 28).

Five neonates developed a seizure disorder. In two it was not controllable. The outcome for this series is shown in Figure 2.

\section{LITERATURE SURVEY}

The literature was reviewed in order to collect those published cases of "hydrocephalus" diagnosed in utero which detail the natural history and/or associated anomalies seen in this condition. One hundred fifteen reported cases were found to have data relevant to this discussion ${ }^{1-31}$ (Tables 2 and 3).

The indications for ultrasound examination were similar to those in the current series however nine cases where discovered on routine scanning $1,2,17,19,27,28$ and eleven cases were diagnosed in pregnancies where there was a past history of

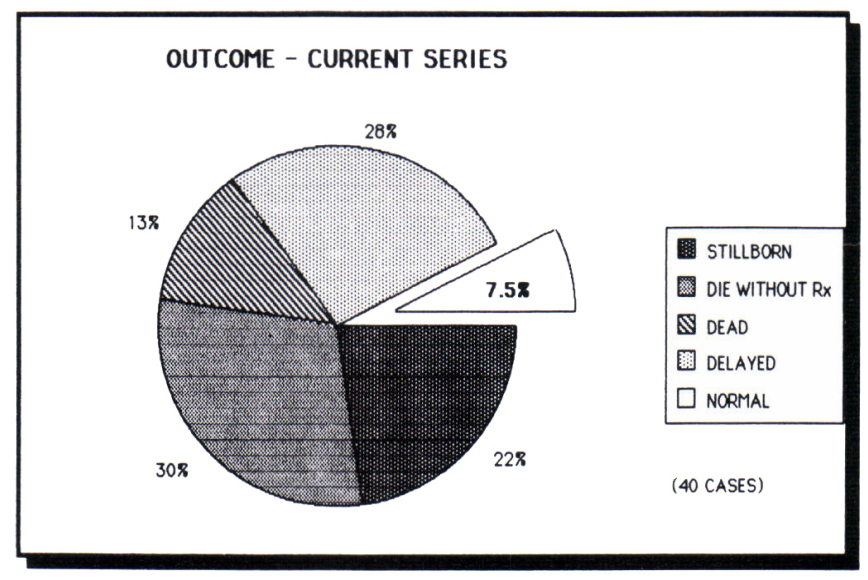

Figure 2-Outcome for the Current Series (40Cases)-Case 28 is excluded. hydrocephalus, spina bifida, hydranencephaly, maternal diabetes or maternal cardiac disease $4,6,8,10,13,20,24,29,31$. The remainder were discovered when examination was undertaken to assess size-date discrepancies, polyhydramnios, antepartum hemorrhage or pain.

Ventriculomegaly was diagnosed on the initial examination of $95 \%$ of these patients. There were six cases where the initial examination was normal but subsequent studies abnor$\mathrm{mal}^{6,17,29,31}$. One case initially felt to be hydrocephalic was subsequently shown to be hyperteloric and to have no midline cerebral structures. In this case the intrauterine diagnosis was revised to holoprosencephaly ${ }^{5}$.

The prenatal recognition of anomalies was in some cases the reason for reporting the case. Dandy-Walker syndrome was seen in 4 cases c $^{7,9,15,19}$, holoprosencephaly in one ${ }^{5}$ and a myelomeningocele in two ${ }^{4,23}$. A frontal encephalocele occurred in one patient ${ }^{17}$ and the hydrolethalus syndrome was diagnosed in eight cases ${ }^{13,28}$. One patient had a facial cleft ${ }^{11}$.

Prenatal treatment was more varied than in our series. The majority of pregnancies were either observed or terminated. Therapeutic encephalocentesis was undertaken in one case' Four cases were shunted in utero ${ }^{2,6,8,11}$.

Fifteen pregnancies were delivered after encephalocentesis; all of these fetuses were stillborn or died early in life ${ }^{3,5,16,18,23,24,26,28,30,31}$. The only exception is a shunted hydranencephalic survivor ${ }^{21}$. All patients shunted in utero were delivered by caesarean section. Six observed pregnancies were delivered prior to term (by dates) for the purpose of earlier postnatal shunting of the hydrocephalus.

As in the current series there were a variety of other abnormalities recognized after birth (Tables 2 and 3). Myelomeningocele, encephalocele, holoprosencephaly and porencephaly were reported. Agenesis of the corpus callosum (alone or with arachnoidal or ventricular cysts) and septum pellucidum were present in several patients, polymicrogyria in one. In only one case was central nervous system infection found and implicated in the causation of the hydrocephalus (Coxsackie B).

Reported facial abnormalities included a facial cleft, micrognathia, cyclopia and cleft palate. The cardiovascular system exhibited abnormalities varying from patent ductus arteriosus to hypoplasia of the heart; ventricular septal defect, tetralogy of Fallot, pulmonary atresia, detrocardia and pericardial effusions.

Gastrointestinal problems included ascites, agenesis of the cystic duct and the gallbladder as well as imperforate anus.

One patient was shown to have a right pelvic kidney.

Skeletal abnormalities included the Klippel-Feil syndrome, thanatophoric dwarfism, syndactyly, and camptodactyly.

The hydrocephalus showed progression, in the majority. This was not invariable. Ten patients had stable hydrocephalus and in two who had been diagnosed in utero, hydrocephalus was not evident after birth.

The known outcome of 112 reported pregnancies is shown in Figure 3. Thirty-five percent of the pregnancies were terminated or the fetus stillborn. Thirty-three percent died following delivery. These had major and fatal congenital malformations.

Of the survivors, $10 \%$ were considered normal at follow$\mathrm{up}^{2,17,25,30,31}$. These patients are reported to have a variety of associated anomalies including myelomeningoceles; the DandyWalker syndrome in one, and in utero Coxsackie B meningitis 


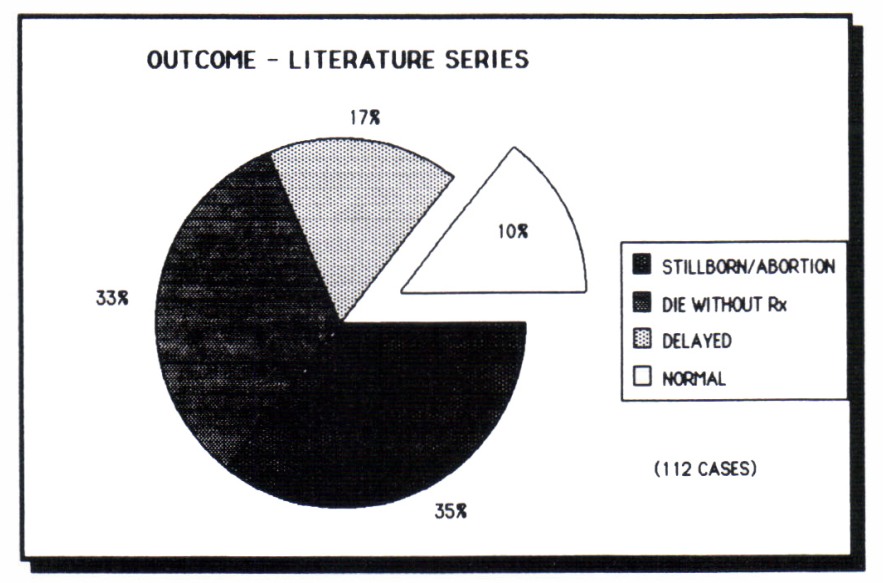

Figure 3 - Outcome for the Literature Series (112 Cases) References: Stillborn or Aborted - 3, 5, 7, 10, 12-18, 22-24, 26-29, 30, 31 Dead Without Treatment - 4, 12, 15, 26, 28, 30, 31

Dead Following Treatment - 11

Developmentally Delayed - 1, 6, 8, 17, 20, 21, 30, 31

Normal - 2, 17, 25, 30, 31

References $-9,11,19$ are excluded from the graph

in another. One shunted fetus who contracted gonococcal ventriculitis following rupture of the membranes is reported as normal at 4 months of age. Two children had arachnoidal cysts and one showed no other other abnormalities. Seventeen percent of the reported cases are delayed to some degree. One infant died from a cardiac arrest complicating uncontrollable seizures, hyperbilirubinemia and presumed diabetes insipidus. Five children were not shunted.

\section{Discussion}

The general availability of ultrasonic imaging techniques for use during pregnancy has, by virtue of the earlier recognition of abnormalities raised many questions regarding both the normal and abnormal development of the fetus in utero, as well as the management of observed pathological processes. The diagnosis of fetal ventriculomegaly is well described in the literature and the criteria for the diagnosis have been published by many authors ${ }^{30-42}$. Unfortunately, the natural history is not well known, nor are the associated anomalies that might affect fetal survival and future development.

Our series is based on diagnoses reached following investigation for obstetrical indications or a positive family history. Routine scanning, however, does not pick up a large number of unrecognized cases. Jorgensen et al. ${ }^{17}$ reported an incidence of ventriculomegaly of $0.16 \%$ in 3120 pregnancies assessed ultrasonographically between 17 and 32 weeks gestation. This incidence is in keeping with the figure of $0.2 \%$ in the pre ultrasound era $^{43}$.

Fetal ventriculomegaly may show one of several patterns of change during pregnancy. While the majority of cases have shown progressive ventricular dilatation with macrocephaly (ie hydrocephalus), this is not the case in all. At least thirteen cases in the literature ${ }^{14,19,20,31}$ and three (cases $2,6,10$ ) of our own demonstrated stable ventriculomegaly on all prenatal followup assessments. More important, however, are the cases of
Neuman ${ }^{22}$, Glick ${ }^{31}$ and one currently being followed in our clinic, where early ultrasonic assessment diagnosed ventriculomegaly, but subsequent studies failed to reveal this anomaly. High risk patients may not exhibit hydrocephalus when studied early in pregnancy. This was the case in two of our patients and five in the literature ${ }^{6,17,27}$. Benke and Strassberg have offered this caution ${ }^{44}$.

Many authors have considered massive hydrocephalus to be a poor prognostic sign for the prediction of eventual development $^{35,45-47}$. This would seem to be the case when "hydrocephalus" is diagnosed in utero. The problem, in utero, is partly, that holoprosencephaly and hydranencephaly are difficult to differentiate from hydrocephalus or ventriculomegaly. Seven such cases are found in our series, all coming to correct diagnosis postnatally. The recognition of other signs such as hypertelorism in alobar holoprosencephaly, and the absence of midline echos in both conditions, may help segregate these usually lethal malformations ${ }^{5}$. The Finnish population seems prone to the "hydrolethalus" syndrome, another cause of absent midline echos ${ }^{13}$. Lobar holoprosencephaly and some cases of hydranencephaly may have abnormal midline echos. These children do not have a good prognosis ${ }^{48}$.

The Dandy-Walker syndrome and its variants have been reported and the postnatal outcome is known ${ }^{49.50}$. X-linked recessive aqueductal stenosis also shows a variety of neuropathological accompaniments and potential outcomes. It has been difficult to predict development in individual cases ${ }^{51,52}$. Tumors $^{20}$ and intraventricular hemorrhages (Case 12) are recognizable. The prognosis of these entities would have to await histological and developmental assessment.

Gross structural anomalies which may influence the infant's prognosis, can remain undetected in utero ${ }^{30,31,56}$. In both the literature and in our series spinal dysraphism and encephaloceles are the commonest such malformations. More subtle developmental errors, which may not influence prognosis but that are reported postnatally, include agenesis of the corpus callosum and septum pellucidium, and polymicrogyria.

Abnormalities of other systems can have a significant bearing on prognosis in the neonate, independent of the hydrocephalus or ventriculomegaly. This is particularly true for cardiac and great vessel abnormalities. Other system abnormalities may not be in and of themselves lethal. The combination however, especially if coupled with prematurity and its complications, may deal a fatal blow.

The overall prognosis from hydrocephalus and ventriculomegaly diagnosed in utero is poor. This comes as no surprise to pediatric neurologists and neurosurgeons who have attended these patients following birth ${ }^{53,54}$. In part this is due to the malformation and its accompaniments as well as its causation ${ }^{55-58}$. The potential for birth trauma and our current postnatal treatment also influence developmental outcome. To minimize the potential for neurological damage, the method of delivery is said to be of importance. This is true for obstetrical encephalocentesis ${ }^{30.31}$; only one of our patients survived. Vaginal delivery in our series was associated with the majority of stillborn fetuses. Elective caesarean section has been recommended to facilitate a less traumatic delivery and to allow early postnatal treatment of hydrocephalus ${ }^{43,56}$. Our series does not allow comment on the validity of early delivery solely for the sake of earlier postnatal treatment of hydrocephalic. Early section may carry with it the dangers of prematurity. 
Treatment options have reached into the womb $b^{2,6.8 .11}$ and into the homes of the general public ${ }^{59}$. Reports of intrauterine shunting in humans, illustrate the fact that shunting in utero has at least the same technical and mechanical problems as does shunting postnatally. Mechanical failures, migrations, obstruction and infection have all occurred. Importantly, the potential development of all children will be influenced by our less than perfect postnatal treatment and its complications ${ }^{60}$.

The recognition of ventriculomegaly in utero has created dilemmas for all parties involved. This condition may be associated with many other anomalies, both within the nervous system and elsewhere. The ventriculomegaly can progress, remain stable or rarely regress. Our ability to predict the survival potential and developmental defects of these fetuses and children remains severely limited.

\section{REFERENCES}

1. Birnholtz JC, Frigoletto FD (1981) Antenatal Treatment of Hydrocephalus. N Engl J Med 303: 1021-1023.

2. Bland RS, Nelson LH, Meiss PJ, Weaver RL, Abramson JS (1983) Gonococcal ventriculitis associated with ventriculoamniotic shunt placement. Am J Obstet Gynecol 147: 781-784.

3. Borno RP, Bon Tempo NC, Kirkendall HL, et al. (1978) Vaginal frank breech delivery of a hydrocephalic fetus after transabdominal encephalocentesis. Am J Obstet Gynecol 132: 336-338.

4. Campbell S, Grundy M, Singer JD (1976) Early antenatal diagnosis of spina bifida in a twin fetus by ultrasound examination and AFP determination. Br Med J 2: 676-678.

5. Chervenak FA, Isaacson G, Mahoney MJ, et al. (1984) The obstetrical significance of holoprosencephaly. Obstet Gynecol 63: 115-121.

6. Clewell WH, Johnson ML, Meirer PR, et al. (1982) A surgical approach to the treatment of fetal hydrocephalus. N Engl J Med 306: 1320-1325.

7. Dempsey PJ, Koch HJ (1981) In utero diagnosis of the DandyWalker Syndrome: Differentiation from extraxial posterior fossa cyst. J Clin Ultrasound 9: 403-405.

8. Depp R, Sabbagha RE, Brown JT, et al. (1983) Fetal surgery for hydrocephalus: Successful in utero ventriculoamniotic shunt for the Dandy-Walker syndrome. Obstet Gynecol 61: 710-714

9. Fileni A, Colosimo C, De Gaetano AM, et al. (1983) DandyWalker Syndrome: Diagnosis in utero by means of ultrasound and CT correlations. Neuroradiology 24: 233-235.

10. Freeman RK, McQuown DS, Secrist LJ, et al. (1977) The diagnosis of fetal hydrocephalus before viability. Obstet Gynecol 49: 109-112.

11. Frigoletto FD, Birnholtz JC, Greene MF (1982) Antnatal treatment of hydrocephalus by ventriculoamniotic shunting. JAMA 248: 2496-2497.

12. Gray R, Barrie H (1978) Decompression of hydrocephalus during delivery. Lancet 2: 52 .

13. Hartikainen-Sorri A, Kirinen P, Herva R (1983) Prenatal detection of the Hydrolethalus Syndrome. Prenat Diagn 3: 219-224.

14. Hartung RW, Yiu-Chiu V (1983) Demonstration of unilateral hydrocephalus in utero. J Ultrasound Med 2: 369-371.

15. Hatjis CG, Horbar JD, Anderson GG (1981) The in utero diagnosis of a posterior fossa intracranial cyst. AM J Obstet Gynecol 140: 473-475.

16. Hyndman J, Johri AM, MacLean NE (1980) Diagnosis of fetal hydrocephalus by ultrasound. NZ Med J 91: 385-386.

17. Jorgensen $C$, Ingemarsson 1, Svenningsen NW (1983) Prenatal diagnosis of fetal brain ventricle dilitation. $\mathrm{Br} \mathrm{J}$ Obstet Gynecol 90: 162-166.

18. Kellner KR, Cruz AC, Gelman SR, et al. (1980) Percutaneous fetal ventriculography. J Reprod Med 24: 225-228.

19. Kirkinen P, Joupilla P, Valkeakari T, et al. (1982) Ultrasonic evaluation of the Dandy-Walker syndrome. Obstet Gynecol 59: 185-215.

20. Kirkinen P, Suramo I, Joupilla P, et al. (1982) Combined use of ultrasound and computed tomography in the evaluation of fetal intracranial abnormality. J Perinat Med 10: 257-265.
21. Lee TG, Warren WH (1977) Antenatal diagnosis of hydranencephaly by ultrasound: Correlation with ventriculography and computed tomography. J Clin Ultrasound 5: 271-273.

22. Newman GC, Buschi AL, Sugg NK, et al., Miller JQ (1982) DandyWalker syndrome diagnosed in utero by ultrasonography. Neurology 32: 180-184.

23. Osathanondh R, Birnholtz JC, Altman AM, et al. (1980) Ultrasonically guided transabdominal encephalocentesis. J Reprod Med 25: 125-128.

24. Patterson JA, Gold WR, Sanz LE, et al. (1981) Antenatal evaluation of fetal hydrocephalus with computed tomography. Am J Obstet Gynecol 140; 344-345.

25. Reed MF (1972) Ultrasound in diagnosing hydrocephalus. B Med J 3: 762 .

26. Robertson CH, Lund RR, Soroosh F, et al. (1969) Percutaneous fetal ventriculography. Obstet Gynecol 34: 841-846.

27. Robertson RD, Sarti DA, Brown WJ (1981) Congenital hydrocephalus in two pregnancies following the birth of a child with a neural tube defect: etiology and management. J Med Genetics 18: 105-107.

28. Salonen R, Herva R, Norio R (1981) The hydrolethalus syndrome: dellineation of a "new" lethal malformation based on 28 patients. Clin Genetics 19: 321-330.

29. Van Egmond-Linden A, Wladimiroff JW, Jahoda MCJ, et al. (1983) Prenatal diagnosis of X-linked hydrocephaly. Prenat Diagn 3: 219-224.

30. Chervenak FA, Duncan C, Ment LR, et al. (1984) Outcome of Fetal Ventriculomegaly. Lancet 2 (8396): 179-181.

31. Glick PL, Harrison MR, Nakayama DK (1984) The management of ventriculomegaly in the fetus. J Pediatr 105: 97-105.

32. Garrett WJ, Fisher CC, Kossoff G (1975) Hydrocephaly, microcephaly and anencephaly diagnosed in pregnancy by ultrasonic echography. Med J Aust 2: 587-589.

33. Denkhaus H, Winsberg F (1979) Ultrasonic measurement of the fetal ventricular system. Radiology 131: 781-787.

34. Dunne MG, Johnson ML (1979) The ultrasonic demonstration of fetal abnormalities in utero. J Reprod Med 23: 195-206.

35. Hobbins JC, Grannun PAT, Berkowitz RL, et al. (1979) Ultrasound in the diagnosis of congenital anomalies. Am J Obstet Gynecol 134: $331-345$.

36. Jeanty P, Dramaix-Wilmet M, Delbeke D, et al. (1981) U'trasonic evaluation of fetal ventricular growth. Neuroradiology 21: 127-131.

37. Hidalgo H, Bowie J, Rosenberg ER, et al. (1982) In utero sonographic diagnosis of fetal cerebral anomalies. Am J Radiol 139: 143-148.

38. Campbell S, Pearce JM (1983) Ultrasound visualization of congenital malformations. Br Med Bull 39: 322-331.

39. Campbell $S$ (1977) Early prenatal diagnosis of neural tube defect by ultrasound. Clin Obstet Gynecol 20: 351-359.

40. Chinn DH, Callen PW, Filly RA (1983) The lateral cerebral ventricle in early second trimester. Radiology 148: 529-531.

41. Hill LM, Breckie R, Gehrking WC (1983) The prenatal detection of congenital malformations by ultrasonography. Mayo Clin Proc 58: 805-826.

42. McGahan JP, Phillips HE (1983) Ultrasonic evaluation of the size of the trigone of the fetal lateral ventricle. J Ultrasound Med 2: 315-319.

43. Ferry PC, Pernoll ML (1976) The rational management of perinatal hydrocephalus. Am J Obstet Gynecol 126: 151-152.

44. Benke P, Strassberg R (1980) Prenatal study of X-linked aqueductal stenosis. J Med Genetics 17: 158.

45. Johnson ML, Pretorius D, Clewell WH, et al. (1983) Fetal hydrocephalus: diagnosis and management. Semin Perinatol 7: 83-89.

46. Nulsen FE, Rekate HL (1982) The results of treatment for hydrocephalus as a guide for future management. In: Pediatric Neurosurgery: Surgery of the Developing Nervous System. Grune and Stratton, New York. pp 229-241.

47. McCullough DC, Balzer-Martin LA (1982) Current prognosis in overt neonatal hydrocephalus. J Neurosurg 57: 378-383.

48. McLone DG (1982) Congenital Malformation of the Brain. In: Pediatric Neurosurgery: Surgery of the Developing Nervous System. Grune and Stratton, New York. pp 105-107.

49. Sawaya R, McLaurin RL (1981) Dandy-Walker Syndrome. Clinical analysis of 23 cases. J Neurosurg 55: 89-97.

50. Tal Y, Freigang B, Dunn HG, et al. (1980) Dandy-Walker Syndrome Analysis of 21 cases. Dev Med Child Neurol 22: 189-201. 
51. Edwards JH, Norman RM, Roberts JM (1961) Sex linked hydrocephalus: report of a family with 15 affected members. Arch Dis Child 36: 481-485.

52. Kelley RI, Zackai EH, Mennuti MT, et al. (1982) Treatment of fetal hydrocephalus. New Engl J Med 307: 1211 (Letter).

53. Donn SM (1982) Fetal hydrocephalus - a perinatal dilemma. J Reprod Med 27: 589-592.

54. Mealey J, Gilmor RL, Budd MP (1973) The prognosis for hydrocephalus overt at birth. J Neurosurg 39: 348-355.

55. Sunder TR (1981) Antenatal treatment of hydrocephalus. New Engl J. Med 305: 403 (Letter).
56. Cochrane DD, Myles ST (1982) Management of intrauterine hydrocephalus. J Neurosurg 57: 590-596.

57. Cochrane DD, Myles ST (1983) Management of intrauterine hydrocephalus. J Neurosurg 58: 793 (Letter).

58. Venes JL (1983) Management of intrauterine hydrocephalus. J Neurosurg 58: 793 (Letter).

59. Hollister A, Tsiarar A (1983) The Unborn Patient. Life 6: 38-44.

60. Hoffman HJ (1982) Technical Problems in Shunts. In: Shunts and Problems in Shunts. Karger, Basel. pp 158-169. 